\title{
B7-H3 on circulating epithelial tumor cells correlates with the proliferation marker, Ki-67, and may be associated with the aggressiveness of tumors in breast cancer patients
}

\author{
MONIKA PIZON, DOROTHEA SONJA SCHOTT, ULRICH PACHMANN and KATHARINA PACHMANN
}

Transfusion Center Bayreuth, D-95448 Bayreuth, Germany

Received July 9, 2018; Accepted August 1, 2018

DOI: $10.3892 /$ ijo.2018.4551

\begin{abstract}
Circulating epithelial tumor cells (CETCs) in peripheral blood are a prerequisite for the development of metastases. B7-H3 is an important immune checkpoint member of the B7 family and inhibits T-cell mediated antitumor immunity. Its expression is associated with a negative prognosis and a poor clinical outcome. Based on the clinical success of inhibitory immune checkpoint blockade, monoclonal antibodies (mAbs) against B7-H3 appear to be a promising therapeutic strategy. The proliferation biomarker, Ki-67, is used as a prognostic factor for breast cancer and reflects the proliferative potential of the tumor. In order to better understand the role of B7-H3 and $\mathrm{Ki}-67$ in cancer development, in this study, we used a real-time biopsy for determining both biomarkers on CETCs in breast cancer patients. Blood from 50 patients suffering from breast cancer was analyzed for CETCs and the expression of B7-H3 and $\mathrm{Ki}-67$ using the maintrac ${ }^{\circledR}$ method. B7-H3 expression on CETCs was found in $82 \%$ of the patients. The frequency of B7-H3- and Ki-67-positive CETCs was significantly higher in patients who had received radiation therapy compared to patients who had not received irradiation. B7-H3-positive CETCs seemed to be more aggressive as the percentage of B7-H3-positive CETCs correlated with the percentage of cells positive for the proliferation marker, Ki-67 $(r=0.72 \mathrm{P}<0.001)$. A significant association between the Ki-67 and B7-H3 expression level on the CETCs and nodal status was observed. On the whole, the findings of this study indicate that breast cancer patients have detectable CETCs with a high frequency of B7-H3 expression regardless of the stage of the disease. B7-H3 seems to be an important factor in immune evasion and may thus be a promising target for anticancer therapies. Radiation may lead to an upregulation of B7-H3 expression on CETCs, which could be a possible mechanism of acquired radio-resistance.
\end{abstract}

Correspondence to: Dr Monika Pizon, Transfusion Center Bayreuth, Kurpromenade 2, D-95448 Bayreuth, Germany

E-mail: mpizon@simfo.de

Key words: B7-H3, circulating epithelial tumor cells, Ki-67, breast cancer

\section{Introduction}

Breast cancer is the most frequently diagnosed malignancy in women (1). Despite improved methods of early detection and diagnosis, as well as usually effective clinical management, breast cancer is the second leading cause of cancer-related mortality due to recurrent metastatic disease (2). Of note, $90 \%$ of breast cancer-related deaths are not due to the primary tumor, but due to metastatic disease. Current models of metastasis support the hypothesis that cells can detach from the primary tumor and move to distant sites via the blood vessels and lymphatic system (3). For this reason, new methods are necessary for the detection and treatment of the residual tumor cells in order to prevent metastasis (4). A large number of studies have documented disseminated tumor cells in the bone marrow or circulating tumor cells in the peripheral blood from patients with most types of epithelial cancer (5-10). The detection and characterization of tumor cells in the peripheral blood have various potential applications in oncology (11). In the early stage of the disease, the enumeration and characterization of circulating tumor cells can potentially help to monitor the effect of systemic therapy, detect an early relapse of malignancy, predict the risk for metastatic disease and, thus, help to improve prognosis $(12,13)$.

In the more advanced stages of the disease, circulating tumor cells may provide prognostic information and aid the physician in monitoring the response to treatment $(14,15)$. Moreover, circulating tumor cells may represent characteristics of the residual tumor, inform about the sensitivity to anticancer drugs and, thus, can be used for a personalized anticancer therapy (16). The phenotypic characterization of tumor cells circulating in the blood has the potential to improve the current understanding of metastasis formation and immune modulation. They can be used as a real-time liquid biopsy in a variety of human cancers and may play a major role in helping to administer a targeted therapy.

B7-H3 is a surface antigen against which a targeted therapy can be envisioned. It is a type I transmembrane protein and an important immune checkpoint member of the B7 ligand family, for which the receptor(s) have not yet been identified. Its expression is induced on immune cells, particularly antigenpresenting cells (17). It is assumed that B7-H3 is involved in the inhibition of T-cells. On the other hand, it has been found that B7-H3 has also stimulatory immunological functions $(18,19)$. 
B7-H3 protein has been detected in several cell lines $(18,20)$ and numerous studies have described B7-H3 expression in human malignancies (17,21-27). Apart from immune evasion, B7-H3 plays a role in cancer progression, including invasion and migration, angiogenesis and gene regulation (19). The proportion of the expression is associated with both a negative prognosis and a poor clinical outcome in patients (17). The blocking immune checkpoints, such as CTLA-4, programmed cell death protein 1 (PD-1) and its ligand, PD-L1, has shown clinical benefit in patients with different tumor entities. Due to its comparable role in immune evasion, $\mathrm{B} 7-\mathrm{H} 3$ has become an interesting target for novel immunotherapeutic treatments $(17,28-30)$.

Ki-67 (also known as MKI67) is a cellular marker that is tightly linked to the cell cycle. The fact that Ki-67 is universally expressed among proliferating cells and is absent in quiescent cells has led to the further evaluation of Ki-67 as a marker of proliferation (31). Although little is known about the exact function of the protein in dividing cells, Ki-67 is expressed during the G1, S and G2 phases of the cell cycle with a peak during mitosis and it is absent in the G0 phase $(32,33)$. There is a strong association between the proportion of Ki-67-positive cells and tumor size, aggressiveness, the level of angiogenesis and the survival of patients. Patients with breast cancer and a Ki-67 index $>15 \%$ have a poor prognosis associated with a shortened disease-free and overall survival (34). On the other hand numerous studies indicate a positive correlation between the percentage of proliferating cells and the response to preoperative treatment with chemotherapy. The higher the level of $\mathrm{Ki}-67$, the more pronounced the sensitivity of breast cancer to neoadjuvant therapy (35). The detection of $\mathrm{Ki}-67$ on circulating epithelial tumor cells (CETCs) may be clinically more informative than the examination of total CETC numbers as it allows for the quantification of proliferative and non-proliferative subpopulations among the CETCs.

The aim of this study was to evaluate B7-H3 and Ki-67 expression on CETCs in breast cancer patients which may contribute to a better understanding of the immune escape mechanisms of these cells. Identifying the proliferative subpopulation of CETCs may serve as a useful tool with which to predict the aggressiveness of cancer.

\section{Patients and methods}

Peripheral blood $(7.5 \mathrm{ml})$ from 50 breast cancer patients in different stages of disease was drawn into blood count tubes with ethylenediamine-tetra-acetic acid (EDTA) as an anticoagulant and processed within $48 \mathrm{~h}$ of collection. Medical records were reviewed for determination of ER/PR and HER2 status in the primary tumor or metastatic biopsy upon diagnosis. The primary tissue was processed in the corresponding hospitals according to the ASCO-CAP guidelines. In parallel, healthy control blood samples were collected from 12 male and 8 female donors aged between $20-40$ years. The sampling of peripheral blood was carried out 6-12 weeks after the end of standard therapy (tumor resection, adjuvant chemotherapy and adjuvant radiotherapy). In patients with local or distant recurrence, blood was collected prior to the treatment for recurrent disease. All patients and healthy volunteers gave their informed consent to participate in the study, which was approved by the Ethics and Scientific Committees of the University of Jena (Jena, Germany).

For CETC enumeration and further characterization, the maintrac ${ }^{\circledR}$ approach was used, as reported previously (36). Briefly, $1 \mathrm{ml}$ blood was subjected to red blood cell lysis using $15 \mathrm{ml}$ of erythrocyte lysis solution (Qiagen, Hilden, Germany) for $15 \mathrm{~min}$ at $4^{\circ} \mathrm{C}$ spun down at $700 \mathrm{x} \mathrm{g}$ and re-diluted in $500 \mathrm{ml}$ of PBS-EDTA. Subsequently, $5 \mu 1$ of fluoresceinisothiocyanate (FITC)-conjugated anti-human epithelial cell adhesion molecule antibody (EpCAM, dilution 1:4, clone HEA-125, cat. no. 130-113-203, Miltenyi Biotec GmbH, Bergisch Gladbach, Germany) at a final concentration of up to $10^{7}$ cells $/ 100 \mu \mathrm{l}$ cell suspension were added and incubated for $15 \mathrm{~min}$ at $4^{\circ} \mathrm{C}$. The corresponding isotypic control for EpCAM (Mouse IgG1K FITC, Miltenyi Biotec GmbH) was used at the same final concentration. The samples were subsequently diluted with $430 \mu \mathrm{l}$ PBS-EDTA. A defined volume of the cell suspension and propidium iodide (PI; Sigma-Aldrich, St. Louis, MO, USA) was transferred to wells of ELISA plates (Greiner Bio-One, Monroe, NC, USA). The analysis of red and green fluorescence of the cells was performed using a Fluorescence Scanning Microscope, ScanR, (Olympus, Tokyo, Japan), enabling the detection and relocation of cells for the visual examination of EpCAM-positive cells. For data analysis, we used the ScanR Analysis software (Olympus). Vital CETCs were defined as EpCAM-positive cells, lacking in nuclear PI staining and with intact morphology, and only these cells were counted (Fig. 1). We used fluorospheres (Flow-Check 770, Beckman Coulter, Brea, CA, USA) for the daily verification of optical components and detectors of the microscope, which are required to ensure the consistent analysis of samples.

The analyses of B7-H3 and Ki-67 expression on the CETCs were performed with an extended maintrac ${ }^{\circledR}$ approach. For B7-H3 expression analysis, we used an anti-human B7-H3 phycoerythrin (PE)-conjugated antibody (dilution 1:10, clone MIH42, cat. no. 351002, BioLegend, San Diego, CA, USA) at a final concentration of $0.9 \mu \mathrm{g} / \mathrm{ml}$ and for $\mathrm{Ki}-67$ we used an anti-human Ki-67 phycoerythrin (PE)-conjugated antibody (dilution 1:10, clone Ki-67, cat. no. 350503, BioLegend) at a final concentration of $0.1 \mu \mathrm{g} / \mathrm{ml}$. The corresponding isotype controls for B7-H3 (Mouse IgG1 PE, cat. no. 400101, BioLegend) and Ki-67 (Mouse IgG1 PE, cat. no. 400111, BioLegend) were used at the same final concentration. Finally, the cells were visually inspected looking for a green and red surface staining, but also a well-preserved nucleus (Fig. 2). For excluding the expression of B7-H3/Ki-67 on hematopoetic cells, we additionally performed staining with EpCAM-FITC, B7-H3-PE/Ki-67-PE and CD45-Pacific blue (clone J.33, dilution 1:1, cat. no. A74763, Beckman Coulter, Krefeld, Germany) antibodies (Fig. 3). The results for B7-H3 and $\mathrm{Ki}-67$ were calculated as a percentage of the total number of CETCs.

MCF-7 and Sk-Br-3 (data not shown) breast cancer cells, which were used as positive controls for Ki-67 analysis, were obtained from the CLS Cell Lines Service (Eppenheim, Germany). The Sk-Br-3 cell line was grown in Dulbecco's modified Eagle's medium with 4,5 g/l glucose, $2 \mathrm{mM}$ L-glutamine (Gibco/Thermo Fisher Scientific, Waltham, MA, USA) and $10 \%$ FBS. The cells were maintained at $37^{\circ} \mathrm{C}$ in $5 \% \mathrm{CO}_{2}$. The 
A
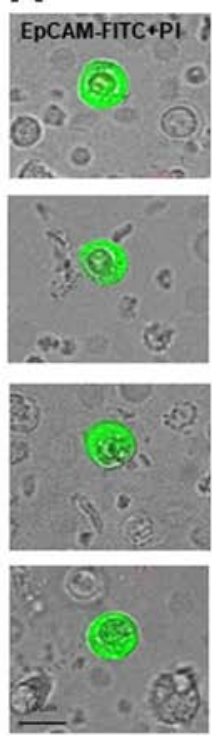
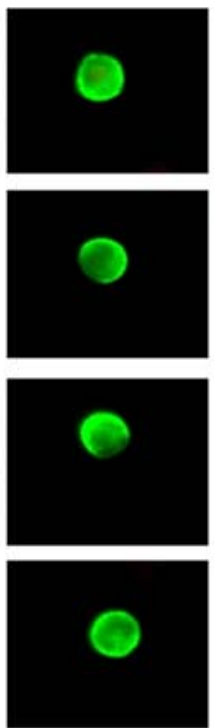
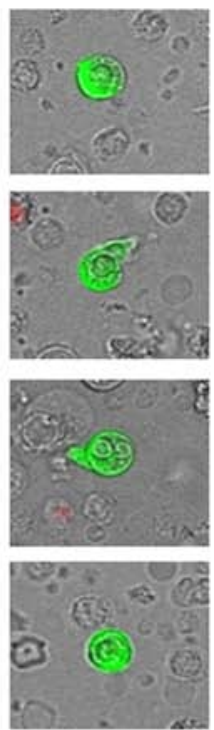
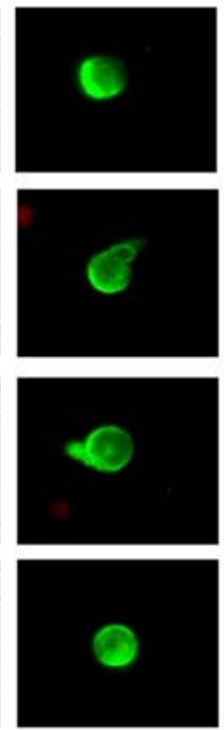

B
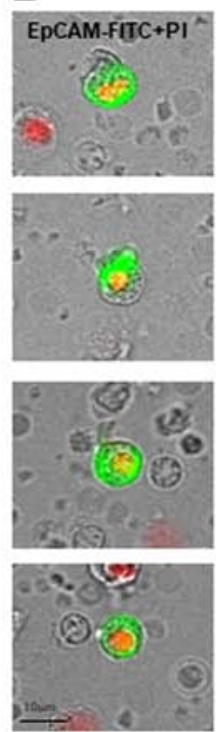
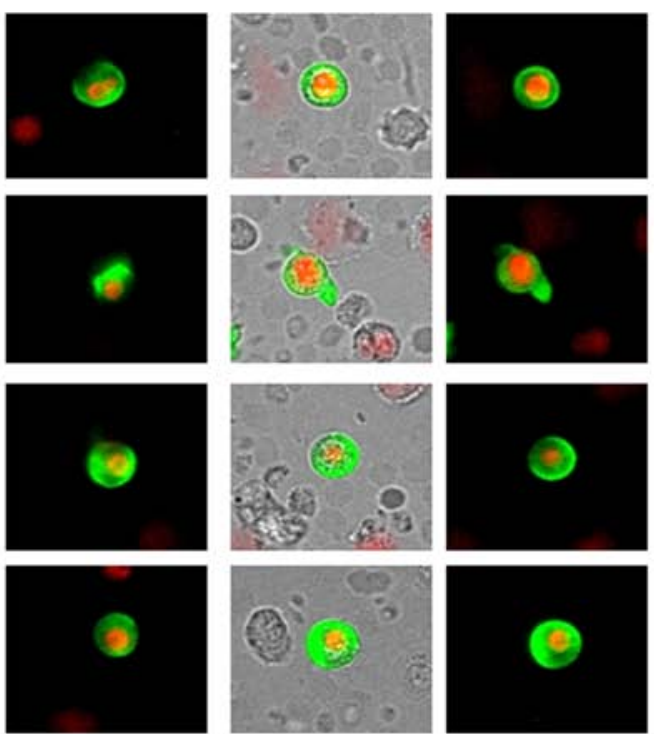
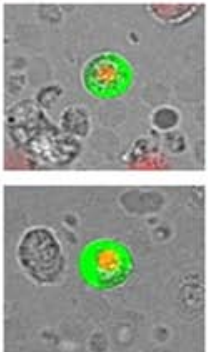
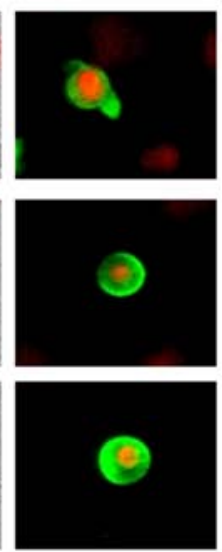

Figure 1. Illustrative images of live and dead CETCs. (A) The live CETCs with a green EpCAM surface staining, a well preserved morphology, but no red intracellular staining by PI are shown. EpCAM-fluorescence varies strongly between the individual cells. (B) Images representing dead CETCs exhibiting red intracellular staining by PI. CETCs, circulating epithelial tumor cells.
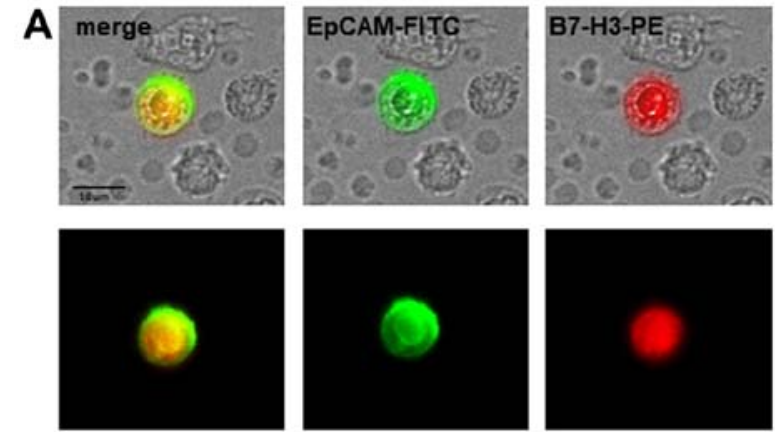
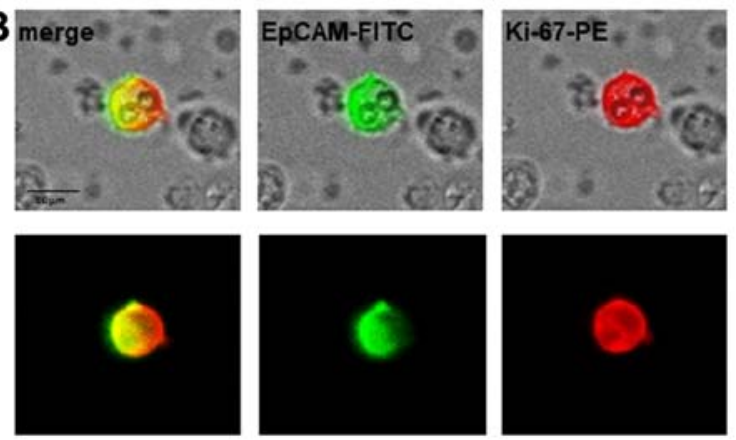

Figure 2. Illustrative CETC images of double antibody staining for (A) EpCAM (green) and B7-H3 (red) and (B) EpCAM (green) and Ki-67 (red). The yellow color is a result of the mixture of green and red due to co-expression at the same site of EpCAM and B7-H3 or Ki-67. CETCs, circulating epithelial tumor cells.
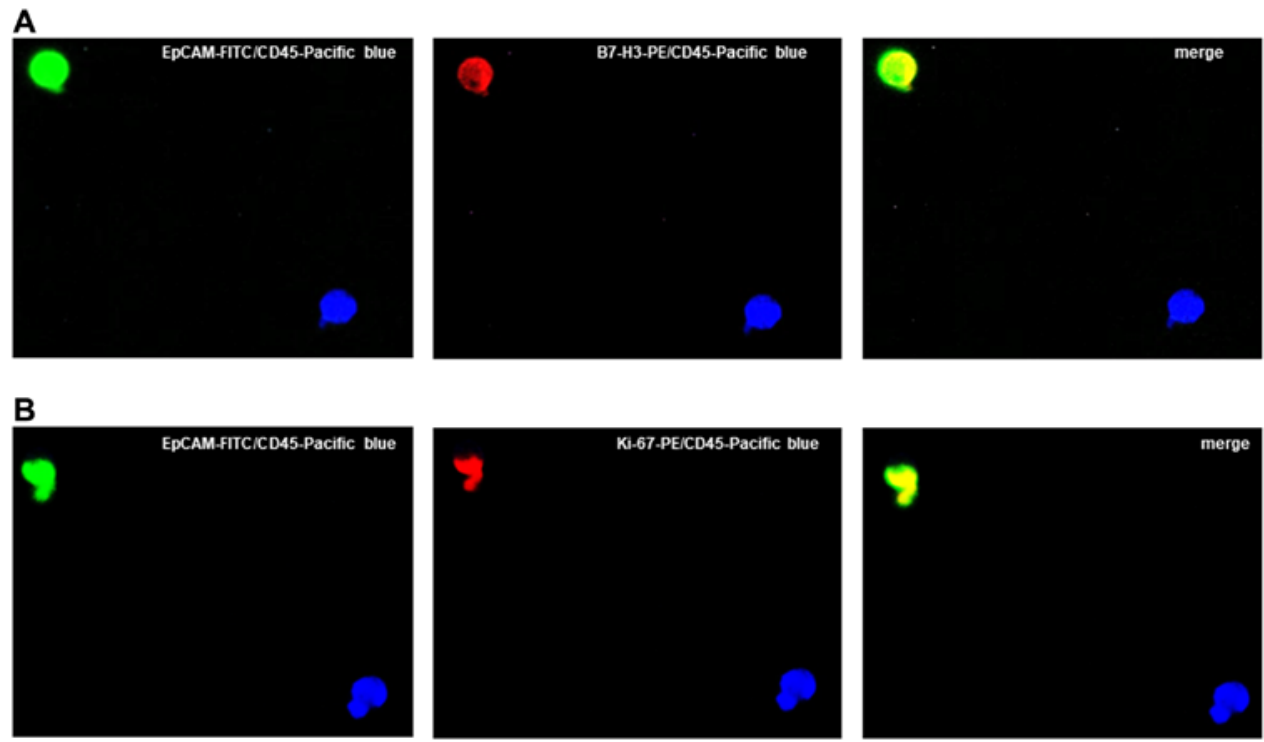

Figure 3. Fluorescence microscope images of (A) B7-H3- and (B) Ki-67-positive CETCs. CETC is positive for EpCAM, B7-H3 or Ki-67 and strictly negative for CD45. The yellow color is a result of the mixture of green and red due to co-expression at the same site of EpCAM and B7-H3 or Ki-67. CETCs, circulating epithelial tumor cells. 

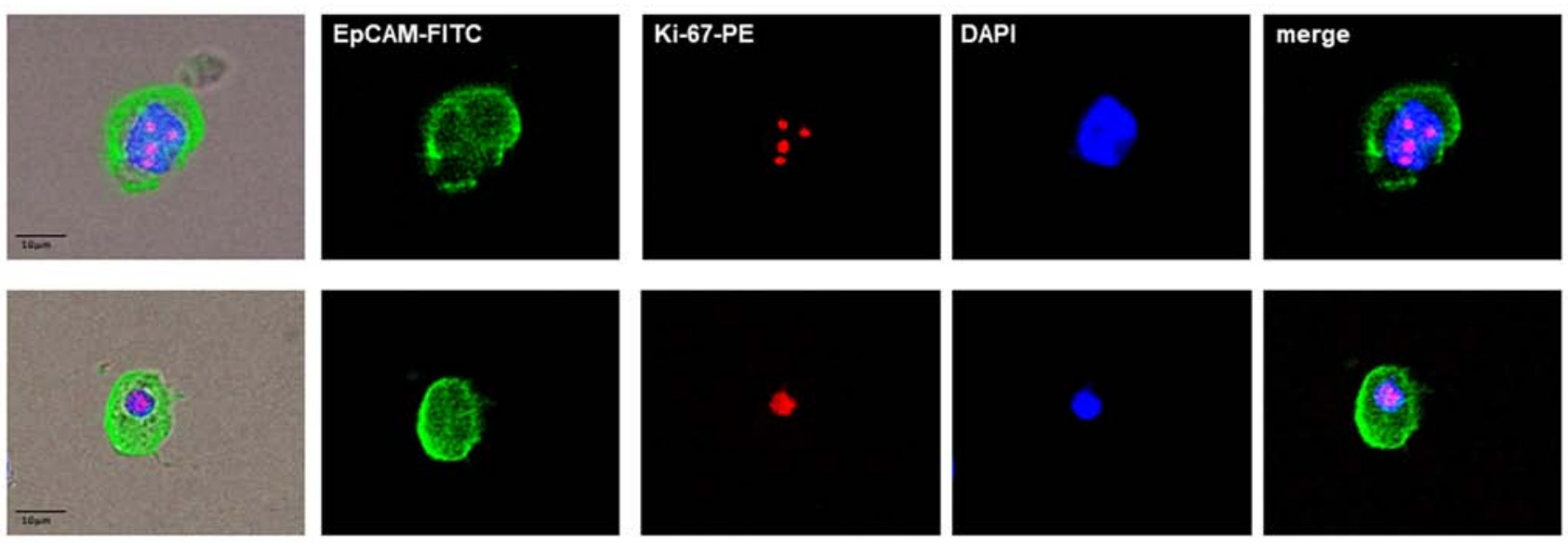

Figure 4. Two examples of Ki-67 staining on the MCF-7 cell line.
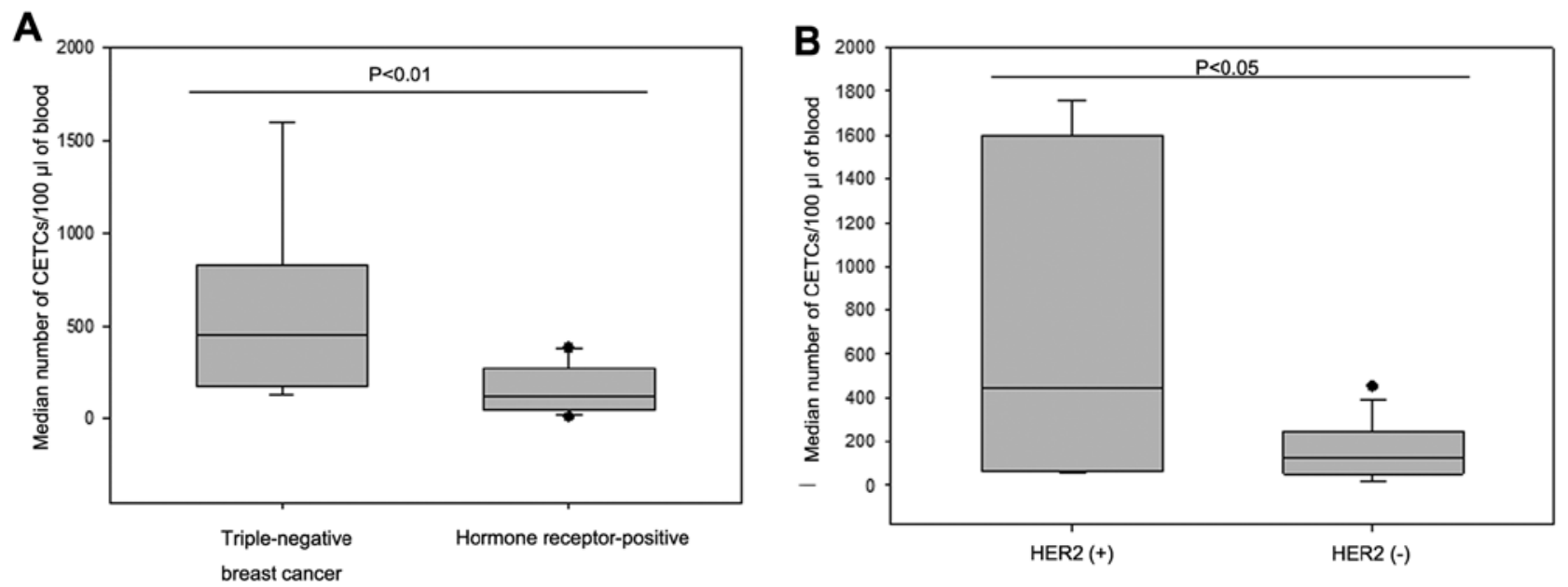

Figure 5. (A) Median number of CETCs in patients with triple-negative and hormone receptor-positive primary tumors; and (B) median number of CETCs in patients with HER2-positive and HER2-negative primary tumors. CETCs, circulating epithelial tumor cells; HER2, human epidermal growth factor receptor 2.

MCF-7 cells were grown in minimum essential medium Eagle ready-to-use medium (CLS Cell Lines Service). For immunofluorescence analysis, the cells were detached from the cell culture flasks using StemPro ${ }^{\circledR}$ Accutase ${ }^{\circledR}$ Cell Dissociation Reagent (Gibco/Thermo Fisher Scientific) washed and stained for $\mathrm{Ki}-67$ with the same protocol as the patient samples (Fig. 4).

Statistical analysis. Statistical analysis was performed using the software programs SigmaPlot version 13.0 (Systat Software Inc., Chicago, IL, USA) for Windows. Comparisons between variables were performed using a Student t-test for normal distributed variables or Mann-Whitney Rank Sum Test for not normally distributed variables. Correlation analysis was carried out was calculated with Pearson's correlation coefficient. The significance level was set at $\mathrm{P}<0.05$.

\section{Results}

A total of 50 patients with histologically confirmed breast cancer were enrolled in this study. Out of these, $25(50 \%)$ patients had T1; $8(16 \%)$ patients had T2 and $11(22 \%)$ patients had T3/4 tumor size. The primary tumors were histologically positive for estrogen receptor (ER) and progesterone receptor (PR) in 30 patients $(60 \%)$ and positive for human epidermal growth factor receptor 2 (HER2) in 11 patients (22\%). In total, $15(30 \%)$ patients were in stage I; $8(16 \%)$ were in stage II; $15(30 \%)$ and $6(12 \%)$ were in stage III and IV, respectively. The age of the patients ranged from 32 to 78 years (median, 59 years). The median number of CETCs was 145 per $100 \mu 1$ of blood (range, 10-1,760). Patients with triple-negative breast cancer (TNBC; $n=7$ ) had significantly more CETCs as compared to hormone receptor-positive patients $(n=30$; median 450 vs. 125 ; $\mathrm{P}<0.01$ ) (Fig. 5A). Additionally, patients with primary HER2-positive tumors $(n=11)$ had significantly more CETCs as compared to patients with HER2-negative tumors $(\mathrm{n}=33$; median 445 vs. 125; $\mathrm{P}<0.05)$ (Fig. 5B). No statistically significant differences in CETC numbers were observed according to tumor size and lymph node/ distantmetastasis (Table I). As a negative control, we tested blood samples from 20 healthy controls and confirmed that none of the samples were positive for CETCs (data not shown). B7-H3-positive CETCs were observed in 43 patients $(86 \%)$. The percentage of $\mathrm{B} 7-\mathrm{H} 3$-positive CETCs ranged from 0 to $80 \%$ (median, $35 \%$ ). An association between hormone 
Table I. Characteristics of cancer patients according to B7-H3 and Ki-67 expression.

\begin{tabular}{|c|c|c|c|c|c|c|}
\hline $\begin{array}{l}\text { Clinicopathological } \\
\text { characteristics }\end{array}$ & $\begin{array}{c}\text { Number of } \\
\text { patients }(\%) \\
\text { with CETCs }\end{array}$ & P-value & $\begin{array}{c}\text { Number of } \\
\text { patients }(\%) \\
\text { with CETCs } \\
\text { positive } \\
\text { for B7-H3 }\end{array}$ & P-value & $\begin{array}{l}\text { Number of } \\
\text { patients }(\%) \\
\text { with CETCs } \\
\text { positive } \\
\text { for Ki-67 }\end{array}$ & P-value \\
\hline Age (years) & & $\mathrm{P}=0.164$ & & $\mathrm{P}=0.745$ & & $\mathrm{P}=0.583$ \\
\hline$\leq 50$ & $10(20)$ & & $10(23)$ & & $9(20)$ & \\
\hline$>50$ & $40(80)$ & & $33(77)$ & & $36(80)$ & \\
\hline Tumor size & & $\mathrm{P}=0.876$ & & $\mathrm{P}=0.168$ & & $\mathrm{P}=0.315$ \\
\hline $\mathrm{T} 1$ & $25(50)$ & & $20(47)$ & & $21(47)$ & \\
\hline $\mathrm{T} 2$ & $8(16)$ & & $7(16)$ & & $8(18)$ & \\
\hline $\mathrm{T} 3 / 4$ & $11(22)$ & & $10(23)$ & & $10(22)$ & \\
\hline n.a. & $6(12)$ & & $6(14)$ & & $6(13)$ & \\
\hline Lymph node status & & $\mathrm{P}=0.424$ & & $\mathrm{P}=0.189$ & & $P<0.05$ \\
\hline Positive & $23(46)$ & & $21(49)$ & & $22(49)$ & \\
\hline Negative & $21(42)$ & & $16(37)$ & & $17(38)$ & \\
\hline n.a. & $6(12)$ & & $6(14)$ & & $6(13)$ & \\
\hline Metastasis & & $\mathrm{P}=0.253$ & & $P=0.616$ & & $\mathrm{P}=0.568$ \\
\hline Positive & $6(12)$ & & $6(14)$ & & $6(13)$ & \\
\hline Negative & $38(76)$ & & $31(72)$ & & $33(74)$ & \\
\hline n.a. & $6(12)$ & & $6(14)$ & & $6(13)$ & \\
\hline ER status & & $P<0.05$ & & $\mathrm{P}=0.178$ & & $P<0.05$ \\
\hline Positive & $30(60)$ & & $23(53)$ & & $25(56)$ & \\
\hline Negative & $14(28)$ & & $14(33)$ & & $14(31)$ & \\
\hline n.a. & $6(12)$ & & $6(14)$ & & $6(13)$ & \\
\hline PR status & & $P<0.05$ & & $\mathrm{P}=0.178$ & & $P<0.05$ \\
\hline Positive & $30(60)$ & & $23(53)$ & & $25(56)$ & \\
\hline Negative & $14(28)$ & & $14(33)$ & & $14(31)$ & \\
\hline n.a. & $6(12)$ & & $6(14)$ & & $6(13)$ & \\
\hline HER2 status & & $P<0.05$ & & $\mathrm{P}=0.412$ & & $P<0.05$ \\
\hline Positive $(2+/ 3+)$ & $11(22)$ & & $10(23)$ & & $11(25)$ & \\
\hline Negative $(0 / 1+)$ & $33(66)$ & & $27(63)$ & & $28(62)$ & \\
\hline n.a. & $6(12)$ & & $6(14)$ & & $6(13)$ & \\
\hline Stage & & $\mathrm{P}=0.181$ & & $\mathrm{P}=0.404$ & & $\mathrm{P}=0.453$ \\
\hline I & $15(30)$ & & $10(23)$ & & $11(25)$ & \\
\hline II & $8(16)$ & & $8(19)$ & & $8(18)$ & \\
\hline III & $15(30)$ & & $13(30)$ & & $14(31)$ & \\
\hline IV & $6(12)$ & & $6(14)$ & & $6(13)$ & \\
\hline n.a. & $6(12)$ & & $6(14)$ & & $6(13)$ & \\
\hline Radiotherapy & & $\mathrm{P}=0.523$ & & $P<0.05$ & & $P<0.05$ \\
\hline Yes & $22(44)$ & & $22(51)$ & & $22(49)$ & \\
\hline No & $26(52)$ & & $19(44)$ & & $21(47)$ & \\
\hline n.a. & $2(4)$ & & $2(5)$ & & $2(4)$ & \\
\hline
\end{tabular}

Bold print denotes the statistically significant P-values.

receptor-status in primary tumors and the percentage of B7-H3-positive CETCs was observed. Patients $(n=14)$ with tumor tissue negative for ER/PR had a significantly greater number of B7-H3-positive CETCs as compared to patients $(n=30)$ with a positive ER/PR status (median $50 \%$ vs. $26 \%$; $\mathrm{P}<0.05)$ (Fig. 6A).

Ki-67-positive CETCs were detected in 45 patients (90\%) and the percentage ranged from 0-100 (median, 45\%). 

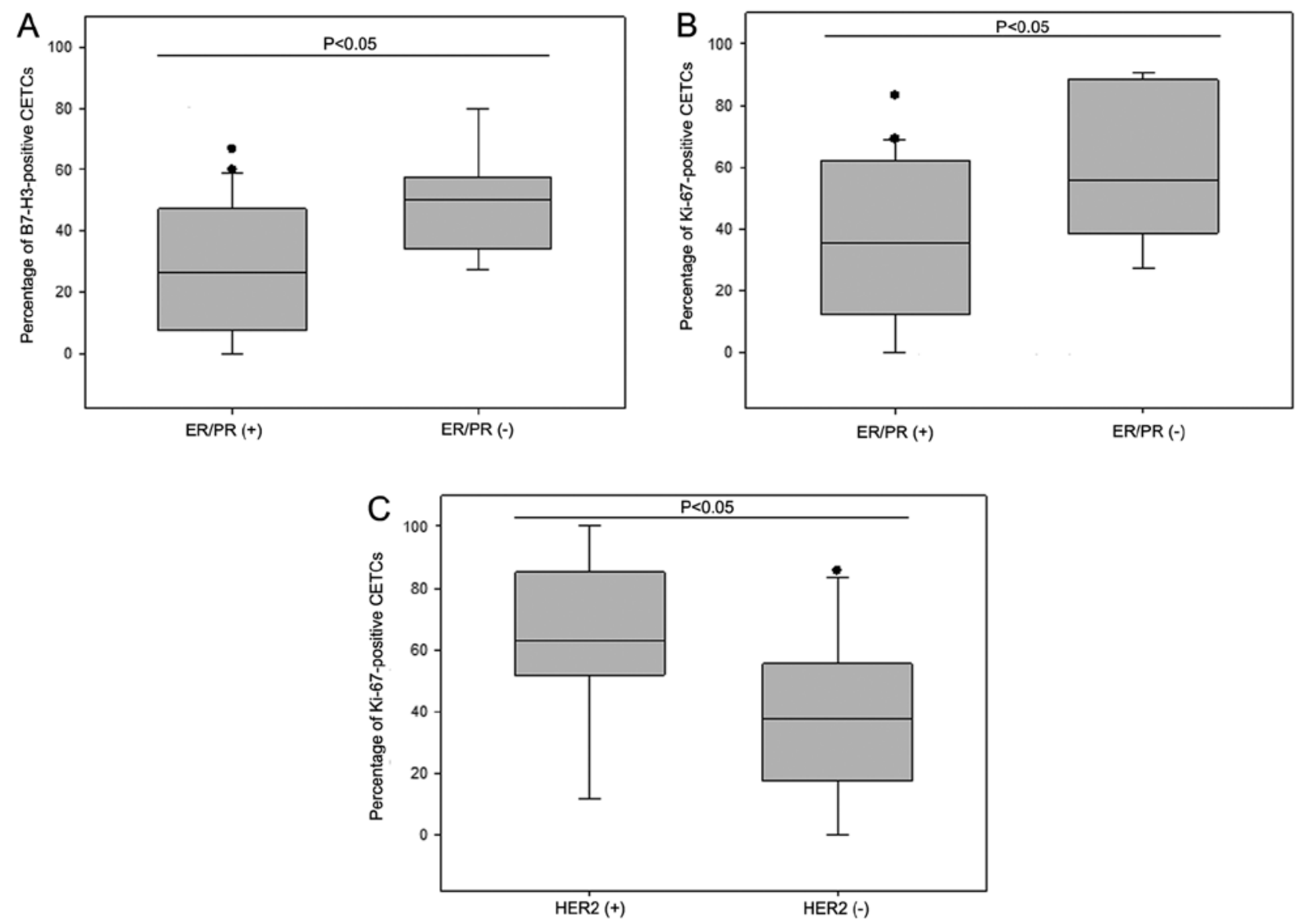

Figure 6. (A) The percentage of B7-H3-, and (B) Ki-67-positive CETCs in patients with HR-positive and HR-negative tumor tissues, and (C) the percentage of Ki-67-positive CETCs in patients with HER2-positive and HER2-negative primary tumors. CETCs, circulating epithelial tumor cells; ER, estrogen receptor; PR, progesterone receptor; HER2, human epidermal growth factor receptor 2.
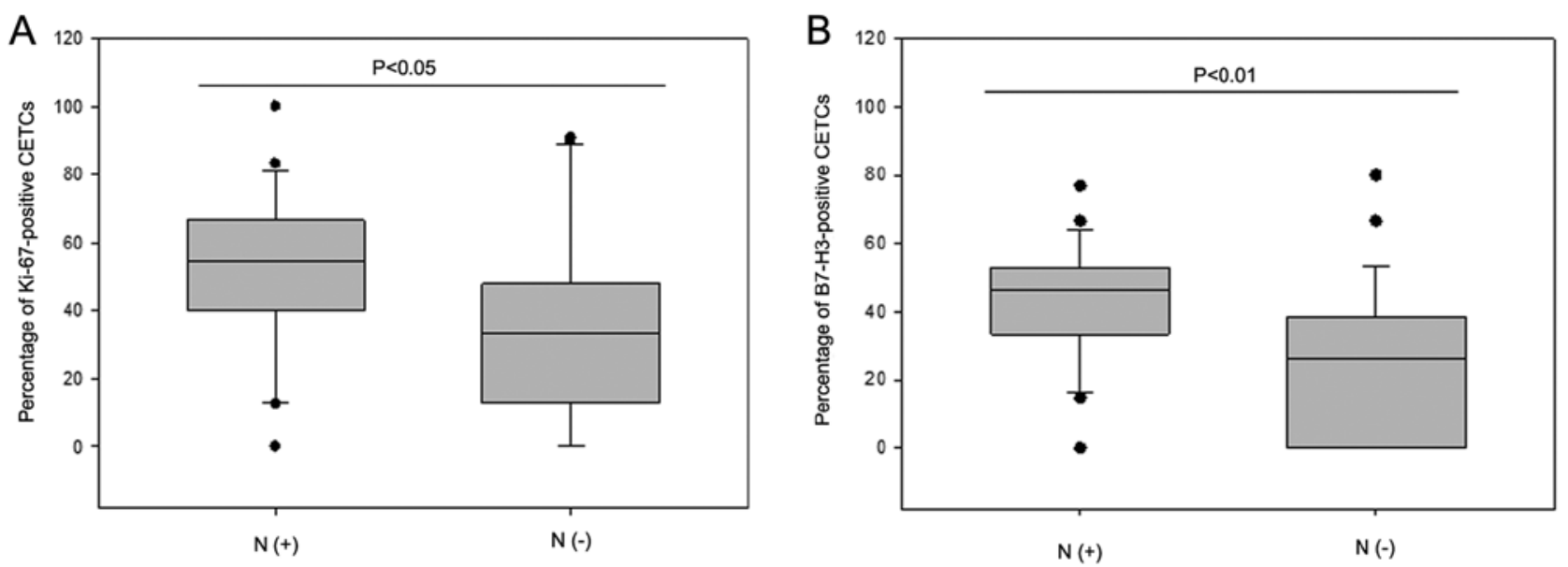

Figure 7. The percentage of (A) Ki-67-, and (B) B7-H3-positive CETCs in patients with positive and negative lymph nodes. CETCs, circulating epithelial tumor cells.

Furthermore, the percentage of Ki-67-positive CETCs was significantly associated with the ER/PR and HER 2 status in the primary tumor. Patients $(n=14)$ with hormone receptor-negative tumors had a greater number of Ki-67-positive CETCs than patients with hormone receptor-positive tumors $(n=30)$ (median, 56\% vs. 35\%; P<0.05) (Fig. 6B). In addition, patients $(n=11)$ with a HER2-positive primary tumor had a greater number of Ki-67-positive CETCs than patients $(\mathrm{n}=33$ ) with a HER2-negative primary tumor (median, 63\% vs. 38\%; $\mathrm{P}<0.05$ ) (Fig. 6C). An association was observed between the percentage of Ki-67 positive CETCs and the lymph node status. Patients $(n=23)$ with positive lymph nodes had a significantly greater number of Ki-67-positive CETCs than patients $(n=21)$ with negative lymph nodes (median, 55\% 

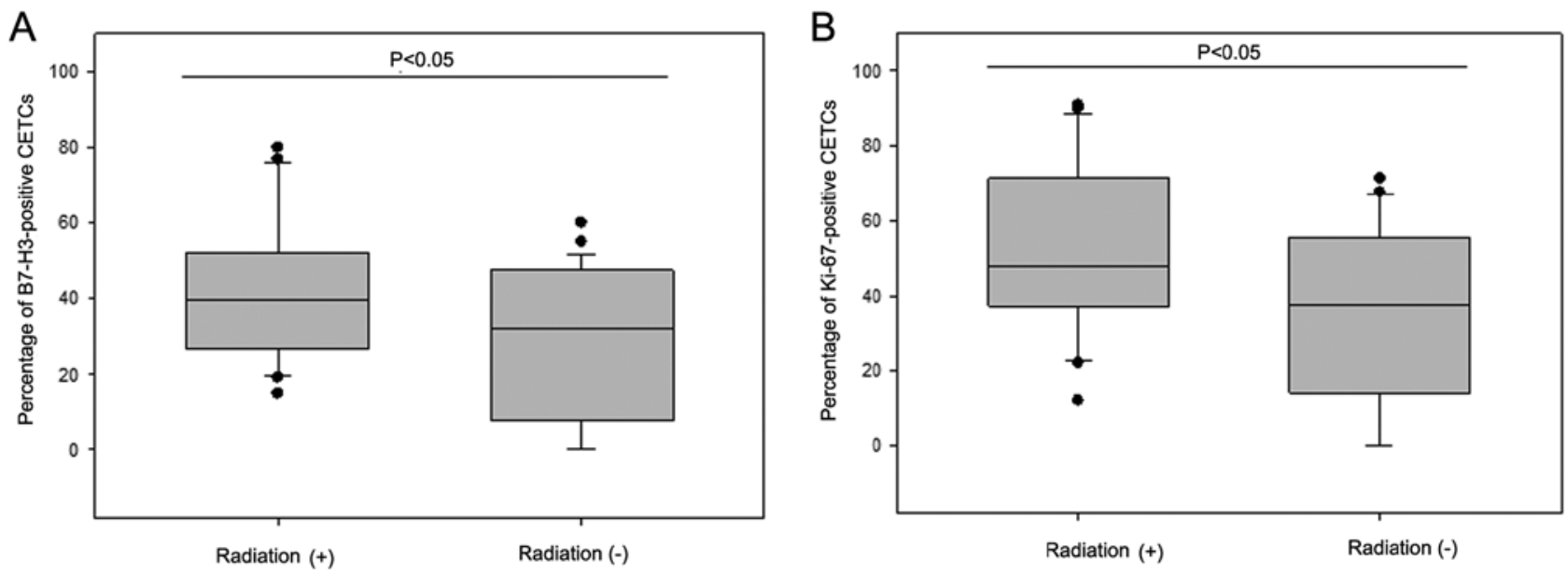

Figure 8. Percentage of (A) B7-H3-, and (B) Ki-67-positive CETCs in patients with and without radiotherapy. CETCs, circulating epithelial tumor cells.

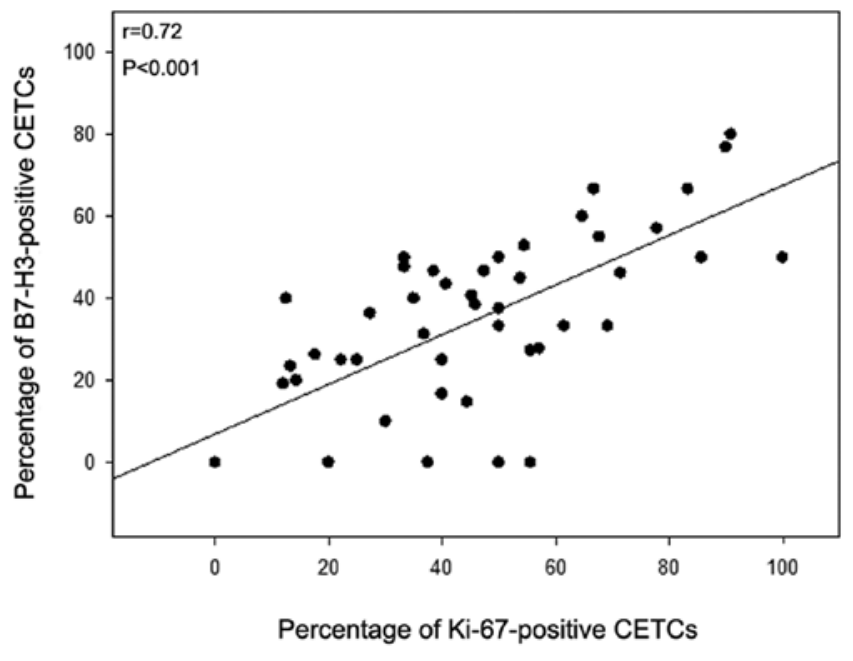

Figure 9. Correlation between the frequency of B7-H3- and the frequency of Ki-67-positive CETCs. CETCs, circulating epithelial tumor cells.

vs. 33\%; $\mathrm{P}<0.05)$ (Fig. 7A). Additionally an association was observed between the percentage of B7-H3-positive CETCs and the lymph node status (median, $46 \%$ vs. $26 \% ; \mathrm{P}<0.01$ ) (Fig. 7B).

Patients $(n=22)$ who had received radiotherapy had a higher fraction of B7-H3- and Ki-67-positive CETCs as compared to patients $(\mathrm{n}=26)$ without radiotherapy (median B7-H3, $40 \%$ vs. 23\%, $\mathrm{P}<0.05$; median Ki-67, $48 \%$ vs. $38 \%, \mathrm{P}<0.05$ ) regardless of the radiation regimen (Fig. 8). Comparing the percentage of B7-H3-positive CETCs with the percentage of Ki-67-positive CETCs, both biomarkers significantly correlated with each other $(\mathrm{r}=0.721 ; \mathrm{P}=0.001)$ (Fig. 9). Statistical analysis revealed that the highest association was observed between the percentage of B7-H3- and Ki-67-positive CETCs $(\mathrm{P}<0.001)$ (Fig. 9), followed by lymph node positivity $(\mathrm{P}=0.013)$ (Fig. 7) and the administration of radiation $(\mathrm{P}=0.038)$ (Fig. 8A). All other parameters were not significant.

Subsequently, we evaluated and compared the percentage of B7-H3- and Ki-67-positive CETCs in 20 breast cancer patients by performing co-expression analysis. The co-expression of
B7-H3 and Ki-67 was confirmed in 90\% of patients. Fig. 10 shows two typical cell galleries of CETCs from one patient which show that these cells have a parallel expression of both, B7-H3 and Ki-67 on their surface. The percentage of B7-H3and $\mathrm{Ki}-67-$ positive CETCs ranged from $23-75 \%$ with a median of $35 \%$ (data not shown).

\section{Discussion}

The analysis of circulating tumor cells is essential for understanding the vascular spread of cancer to distant sites and for being able to make use of these cells for real-time and non-invasive tumor monitoring. A number of techniques have been developed over the past 20 years to detect, isolate and characterize circulating tumor cells (37). Circulating tumor cell analysis may play an important role as a 'liquid biopsy', which will allow physicians to follow changes of the systemic part of the disease over time, enabling adjustment of treatment and thus a promising new diagnostic tool for patients suffering from e.g., breast cancer (36). The majority of the procedures have, however, been hampered by the paucity of these cells recovered by the different approaches particularly those using magnetic bead enrichment after a fixation step (38), which impedes statistical analysis of the circulating tumor cells (39). Apart from mere quantitative analysis, current research on circulating tumor cells is focusing on the identification of novel diagnostic and therapeutic biomarkers expressed by these cells, such as B7-H3 and Ki-67 on tumor cells circulating in the blood, which allows for the determination of the aggressiveness of the residual tumor load, and can thus contribute to the determination of prognosis. They reflect the biological properties of the remnant tumor left in the body after previous interventions, which are crucial for the further development of the disease and can provide starting points for targeted treatment.

The association between the total number of circulating tumor cells and immunohistochemistry in breast cancer is controversial. Punnoose et al reported lower numbers of circulating tumor cells in TNBC as compared to luminal subtypes (40). By contrast, Peeters et al found no significant association between immunohistochemically defined subtypes 

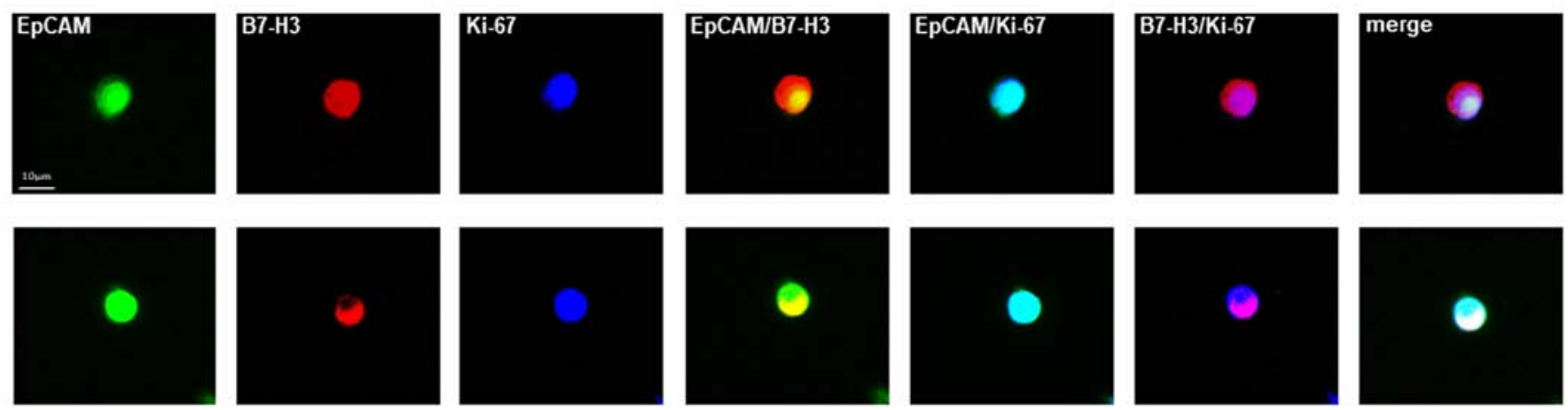

Figure 10. Fluorescence co-localization of EpCAM (green), B7-H3 (red) and Ki-67 (blue) on the CETCs in two representative results from one patient.

and circulating tumor cell numbers, but very high cell counts of $>80$ circulating tumor cells in $7.5 \mathrm{ml}$ blood were found more frequently in patients with Luminal A and TNBC metastatic tumors (41). In this study, using a non-enrichment approach, the number of CETCs was significantly higher in patients with TNBC consistent with the clinical findings that this type of tumor is more aggressive and has an increased potential to be invasive, to migrate and to metastasize. Additionally, we observed a significant difference in the absolute CETC count in patients with HER2-positive tumors who had higher CETC counts as compared to patients with HER2-negative tumors. Our results are contradictory to the results by Liu et al (42) and Giordano et al (43) who reported a lower circulating tumor cell count in HER2-positive subgroups. These discrepancies may be explained by the different methods used for the enumeration of circulating tumor cells.

Due to the growing interest in immunotherapy, the analysis of B7-H3 expression in the primary breast tumor and on the circulating tumor cells may be crucial. B7-H1, known as PD-L1, is one of the most studied targets in present clinical trials. There is a high homology between B7-H3 and B7-H1; therefore, the blockade of both these molecules is highly feasible $(17,18)$. Different antibodies which inhibit B7-H3 are currently being investigated in clinical trials [e.g., 8H9: NCT01099644, NCT01502917, and NCT00089245; enoblituzumab (MGA271): NCT01391143] (19). The present study was designed to demonstrate for the first time, at least to the best of our knowledge, B7-H3 expression in connection with $\mathrm{Ki}-67$ on CETCs in patients with breast cancer. We were able to show that B7-H3 was expressed on a fraction of CETCs in the majority $(82 \%)$ of breast cancer patients. Comparably, Maeda et al (18) detected B7-H3 expression in 92\% of breast cancer tissues at various levels and Sun et al found that B7-H3 expression was present in $80.55 \%$ of breast cancer tissues compared to $16.48 \%$ in normal breast tissues (28). Arigami et al demonstrated a strong expression of B7-H3 in $39 \%$ of breast cancers and the expression was related to the progression of primary breast cancer to axillary lymph nodes (30). In gastric cancer, Arigami et al found that B7-H3 expression can be a useful blood marker for predicting tumor progression (44).

On the single cell level, on average of $30 \%$ of the CETCs expressed B7-H3 in our patient population. There is little data with respect to the expression of B7-H3 on circulating tumor cells in breast cancer patients and none regarding the extent of expression on these cells, at least to the best of our knowledge. Arigami et al (30) only reported on mRNA expression for B7-H3, but this did not allow for the calculatation at the single tumor cell level.

This study suggests that B7-H3 expression in breast cancer is significantly higher in hormone receptor-negative patients, whereas Liu et al and Sun et al found no association between B7-H3 positivity in breast tumor tissue and ER or PR status, histological subtype or differentiation $(23,45)$. The association between B7-H3 on CETCs and hormone receptor status may contribute to explain the worse prognosis of patients with hormone-negative tumors.

The proliferation biomarker, $\mathrm{Ki}-67$, is established as a prognostic factor for breast cancer. The proportion of dividing cells reflects the proliferative potential of the tumor. The expression of $\mathrm{Ki}-67$ in healthy breast tissue is very low $(<3 \%)$. By contrast, in breast cancer tissues, Ki-67 is often overexpressed $(33,46)$. Müller et al using the CellSearch approach reported no expression of $\mathrm{Ki}-67$ in the circulating tumor cells detected in the 47 examined patients (47). This may be due to the low frequency and low number of circulating tumor cells detected by their approach. By contrast, Spiliotaki et al (48), using a different approach, found $\mathrm{Ki}-67$ positive cells in $27.5 \%$ out of 40 circulating tumor cell positive patients. Kallergi et al, using the same approach as Spiliotaki et al, observed Ki-67 positive circulating tumor cells in 51.7 and $44 \%$ of patients with early and metastatic breast cancer, respectively (49). In this study, we found positive staining for Ki-67 on the CETCs in 45 of 50 patients $(90 \%)$. This difference may be explained by the different technologies used to detect circulating tumor cells.

Furthermore, we also found an association between a higher frequency of Ki-67-positive CETCs and a negative ER/PR and positive HER2 status. Similar results were observed in breast cancer tissue by Nishimura et al, where a higher Ki-67 index was significantly associated with a larger tumor, younger age, positive lymph nodes, a higher nuclear grade, a negative ER/PR status, p53 overexpression and a positive HER2 status (50). In addition, they reported that a high Ki-67 index in breast cancer tissue was significantly associated with positive lymph nodes (50). In this study, the expression of Ki-67 on CETCs was statistically significantly associated with a positive lymph node status. Furthermore, comparable to the findings of Arigami et al, the percentage of B7-H3-positive CETCs was significantly associated with a positive lymph node status (30). 
Liu et al found an association between B7-H3 expression in tumor tissue and a positive lymph node metastasis (45). B7-H3 overexpression in CETCs may thus be important for tumor progression and invasiveness.

Post-surgery adjuvant therapies, such as chemo- and radiotherapy are essential for patients with breast cancer; however, many patients suffer from local recurrence or metastasis. In this study, we observed that patients who have received radiotherapy had an upregulated expression of B7-H3 on CETCs. This may be due to inflammatory processes occurring during radiotherapy. Maeda et al demonstrated that $\mathrm{B} 7-\mathrm{H} 3$ was induced by inflammatory cytokines in dendritic cells and monocytes (18). Additionally, Sun et al demonstrated that the stimulation of hepatocellular carcinoma cells with interferon- $\gamma$ in vitro led to a significant upregulation of B7-H3 expression (51). Subsequent radiotherapy resistance observed in breast cancer patients may be due to the upregulation of B7-H3 in CETCs. Combination therapies with B7-H3 blockade may in the future be able to overcome radio-resistance. Of note, in this study, we found that not only B7-H3, but also Ki-67 were more highly expressed in the CETCs in patients who had received radiotherapy. Although there are data available about changes in Ki-67 index during radiotherapy in breast tumor tissue (52), a comparison between tumor tissue and circulating tumor cells has not been made to date, at least to the best of our knowledge. It is well known that a high $\mathrm{Ki}-67$ index in tumor tissue is associated with lower disease-free and overall survival rates in breast cancer (50).

In samples with a $>50 \%$ fraction of $\mathrm{B} 7-\mathrm{H} 3$ expression and Ki-67 expression, a correlation between B7-H3 and Ki-67 can be assumed in individual CETCs. The exact physiological and pathological function of B7-H3 and particularly its role in the development and progression of human cancers remains unclear, as both stimulatory and inhibitory properties have been described (53). B7-H3 may serve as an inhibitor of antitumor immunity. Thus, proliferation may induce B7-H3 and at the same time protect CETCs from destruction by self-reactive T lymphocytes. Understanding the mechanisms through which B7-H3 can be induced in and is association with the proliferation of CETCs may, in the future, contribute the designing of suitable drugs for breast cancer therapy.

The limitations of the study include the small patient sample size and the preponderance of patients in early stage of breast cancer. On the other hand, the possibility of detection of circulating tumor cells also in this patient population may be of advantage as they are still in a situation where a cure is possible.

In conclusion, the analysis of the properties of CETCs offers a low invasive, easy-to-repeat, real-time 'liquid biopsy' approach, which reflects the actual aggressiveness of the tumor. Furthermore, we demonstrate for the first time, at least to the best of our knowledge, that $\mathrm{B} 7-\mathrm{H} 3$ and $\mathrm{Ki}-67$ are expressed on the CETCs in patients with breast cancer. The B7-H3 pathway regulates the innate and adaptive immunity and promotes cancer cell aggressiveness through various immunological functions. Therefore it could become a unique and interesting target for future cancer immunotherapies.

\section{Acknowledgements}

Not applicable.

\section{Funding}

No funding was received.

\section{Availability of data and materials}

The datasets used and/or analyzed during the current study are available from the corresponding author on reasonable request.

\section{Authors' contributions}

MP and KP designed the study. MP and DSS performed the experiments. MP, DSS and UP analyzed the data. MP and DSS wrote the paper in consultation with KP and UP. All authors discussed the results and contributed to the final manuscript.

\section{Ethics approval and consent to participate}

All patients and healthy volunteers gave their informed consent to participate in the study, which was approved by the Ethics and Scientific Committees of the University of Jena (Jena, Germany).

\section{Patient consent for publication}

Not applicable.

\section{Competing interests}

The authors declare that they have no competing interests.

\section{References}

1. Siegel R, Naishadham D and Jemal A: Cancer statistics, 2012. CA Cancer J Clin 62: 10-29, 2012.

2. Davison Z, de Blacquière GE, Westley BR and May FE: Insulin-like growth factor-dependent proliferation and survival of triple-negative breast cancer cells: Implications for therapy. Neoplasia 13: 504-515, 2011.

3. Pantel K and Brakenhoff RH: Dissecting the metastatic cascade. Nat Rev Cancer 4: 448-456, 2004.

4. Swaby RF and Cristofanilli M: Circulating tumor cells in breast cancer: A tool whose time has come of age. BMC Med 9: 43, 2011.

5. Mathiesen RR, Borgen E, Renolen A, Løkkevik E, Nesland JM, Anker G, Ostenstad B, Lundgren S, Risberg T, Mjaaland I, et al: Persistence of disseminated tumor cells after neoadjuvant treatment for locally advanced breast cancer predicts poor survival. Breast Cancer Res 14: R117, 2012.

6. Hartkopf AD, Taran F-A, Wallwiener M, Hagenbeck C, Melcher C, Krawczyk N, Hahn M, Wallwiener D and Fehm $\mathrm{T}$ : The presence and prognostic impact of apoptotic and nonapoptotic disseminated tumor cells in the bone marrow of primary breast cancer patients after neoadjuvant chemotherapy. Breast Cancer Res 15: R94, 2013.

7. Berg A, Berner A, Lilleby W, Bruland ØS, Fosså SD, Nesland JM and Kvalheim G: Impact of disseminated tumor cells in bone marrow at diagnosis in patients with nonmetastatic prostate cancer treated by definitive radiotherapy. Int J Cancer 120: 1603-1609, 2007.

8. Cristofanilli M,Budd GT,Ellis MJ,Stopeck A,Matera J,MillerMC, Reuben JM, Doyle GV, Allard WJ, Terstappen LWMM, et al: Circulating tumor cells, disease progression, and survival in metastatic breast cancer. N Engl J Med 351: 781-791, 2004.

9. Ma XL, Xiao ZL, Liu L, Liu XX, Nie W, Li P, Chen NY and Wei YQ: Meta-analysis of circulating tumor cells as a prognostic marker in lung cancer. Asian Pac J Cancer Prev 13: 1137-1144, 2012. 
10. Rahbari NN, Aigner M, Thorlund K, Mollberg N, Motschall E Jensen K, Diener MK, Büchler MW, Koch M and Weitz J: Meta-analysis shows that detection of circulating tumor cells indicates poor prognosis in patients with colorectal cancer. Gastroenterology 138: 1714-1726, 2010.

11. Dotan E, Cohen SJ, Alpaugh KR and Meropol NJ: Circulating tumor cells: Evolving evidence and future challenges. Oncologist 14: 1070-1082, 2009.

12. Pachmann K, Camara O, Kavallaris A, Krauspe S, Malarski N, Gajda M, Kroll T, Jörke C, Hammer U, Altendorf-Hofmann A, et al: Monitoring the response of circulating epithelial tumor cells to adjuvant chemotherapy in breast cancer allows detection of patients at risk of early relapse. J Clin Oncol 26: 1208-1215, 2008.

13. Pierga JY, Bidard FC, Mathiot C, Brain E, Delaloge S, Giachetti S de Cremoux P, Salmon R, Vincent-Salomon A and Marty M: Circulating tumor cell detection predicts early metastatic relapse after neoadjuvant chemotherapy in large operable and locally advanced breast cancer in a phase II randomized trial. Clin Cancer Res 14: 7004-7010, 2008.

14. Budd GT, Cristofanilli M, Ellis MJ, Stopeck A, Borden E, Miller MC, Matera J, Repollet M, Doyle GV, Terstappen LW, et al: Circulating tumor cells versus imaging - predicting overall survival in metastatic breast cancer. Clin Cancer Res 12: 6403-6409, 2006

15. Dawood S, Broglio K, Valero V, Reuben J, Handy B, Islam R, Jackson S, Hortobagyi GN, Fritsche H and Cristofanilli M: Circulating tumor cells in metastatic breast cancer: From prognostic stratification to modification of the staging system? Cancer 113: 2422-2430, 2008.

16. Paterlini-Brechot $\mathrm{P}$ and Benali NL: Circulating tumor cells (CTC) detection: Clinical impact and future directions. Cancer Lett 253: 180-204, 2007.

17. Picarda E, Ohaegbulam KC and Zang X: Molecular pathways: Targeting B7-H3 (CD276) for human cancer immunotherapy. Clin Cancer Res 22: 3425-3431, 2016.

18. Maeda N, Yoshimura K, Yamamoto S, Kuramasu A, Inoue M, Suzuki N, Watanabe Y, Maeda Y, Kamei R, Tsunedomi R, et al: Expression of B7-H3, a potential factor of tumor immune evasion in combination with the number of regulatory $\mathrm{T}$ cells, affects against recurrence-free survival in breast cancer patients. Ann Surg Oncol 21 (Suppl 4): S546-S554, 2014.

19. Castellanos JR, Purvis IJ, Labak CM, Guda MR, Tsung AJ, Velpula KK and Asuthkar S: B7-H3 role in the immune landscape of cancer. Am J Clin Exp Immunol 6: 66-75, 2017

20. Wang Z, Yang J, Zhu Y, Zhu Y, Zhang B and Zhou Y: Differential expression of $2 \operatorname{IgB} 7-\mathrm{H} 3$ and $4 \operatorname{IgB} 7-\mathrm{H} 3$ in cancer cell lines and glioma tissues. Oncol Lett 10: 2204-2208, 2015.

21. Wang J, Chong KK, Nakamura Y, Nguyen L, Huang SK, Kuo C, Zhang W, Yu H, Morton DL and Hoon DS: B7-H3 associated with tumor progression and epigenetic regulatory activity in cutaneous melanoma. J Invest Dermatol 133: 2050-2058, 2013.

22. Hu Y, Lv X, Wu Y, Xu J, Wang L, Chen W, Zhang W, Li J, Zhang S and Qiu H: Expression of costimulatory molecule B7-H3 and its prognostic implications in human acute leukemia. Hematology 20: 187-195, 2015.

23. Sun J, Guo Y-D, Li X-N, Zhang Y-Q, Gu L, Wu P-P, Bai GH and Xiao Y: B7-H3 expression in breast cancer and upregulation of VEGF through gene silence. OncoTargets Ther 7: 1979-1986, 2014.

24. Zang X, Thompson RH, Al-Ahmadie HA, Serio AM, Reuter VE, Eastham JA, Scardino PT, Sharma P and Allison JP: B7-H3 and $\mathrm{B} 7 \mathrm{x}$ are highly expressed in human prostate cancer and associated with disease spread and poor outcome. Proc Natl Acad Sci USA 104: 19458-19463, 2007.

25. Zang X, Sullivan PS, Soslow RA, Waitz R, Reuter VE, Wilton A, Thaler HT, Arul M, Slovin SF, Wei J, et al: Tumor associated endothelial expression of B7-H3 predicts survival in ovarian carcinomas. Mod Pathol 23: 1104-1112, 2010.

26. Chen Y, Sun J, Zhao H, Zhu D, Zhi Q, Song S, Zhang L, He S, Kuang Y, Zhang Z, et al: The coexpression and clinical significance of costimulatory molecules B7-H1, B7-H3, and B7-H4 in human pancreatic cancer. OncoTargets Ther 7: 1465-1472, 2014

27. Ingebrigtsen VA, Boye K, Nesland JM, Nesbakken A Flatmark K and Fodstad $\varnothing$ : B7-H3 expression in colorectal cancer: Associations with clinicopathological parameters and patient outcome. BMC Cancer 14: 602, 2014.

28. Sun J, Chen LJ, Zhang GB, Jiang JT, Zhu M, Tan Y, Wang HT, $\mathrm{Lu} \mathrm{BF}$ and Zhang XG: Clinical significance and regulation of the costimulatory molecule B7-H3 in human colorectal carcinoma. Cancer Immunol Immunother 59: 1163-1171, 2010.
29. Yamato I, Sho M, Nomi T, Akahori T, Shimada K, Hotta K, Kanehiro H, Konishi N, Yagita H and Nakajima Y: Clinical importance of B7-H3 expression in human pancreatic cancer. Br J Cancer 101: 1709-1716, 2009.

30. Arigami T, Narita N, Mizuno R, Nguyen L, Ye X, Chung A, Giuliano AE and Hoon DS: B7-h3 ligand expression by primary breast cancer and associated with regional nodal metastasis. Ann Surg 252: 1044-1051, 2010.

31. Li FY, Wu SG, Zhou J, Sun JY, Lin Q, Lin HX, Guan XX and He ZY: Prognostic value of Ki-67 in breast cancer patients with positive axillary lymph nodes: A retrospective cohort study. PLoS One 9: e87264, 2014.

32. Dowsett M, Nielsen TO, A'Hern R, Bartlett J, Coombes RC, Cuzick J,Ellis M,Henry NL,Hugh JC,Lively T, et al; International $\mathrm{Ki}-67$ in Breast Cancer Working Group: Assessment of Ki67 in breast cancer: Recommendations from the International Ki67 in Breast Cancer working group. J Natl Cancer Inst 103: 1656-1664, 2011.

33. Tan PH, Bay BH, Yip G, Selvarajan S, Tan P, Wu J, Lee CH and Li KB: Immunohistochemical detection of Ki67 in breast cancer correlates with transcriptional regulation of genes related to apoptosis and cell death. Mod Pathol 18: 374-381, 2005.

34. Goldhirsch A, Ingle JN, Gelber RD, Coates AS, Thürlimann B and Senn HJ; Panel members: Thresholds for therapies: Highlights of the St Gallen International Expert Consensus on the primary therapy of early breast cancer 2009. Ann Oncol 20: 1319-1329, 2009

35. Yerushalmi R, Woods R, Ravdin PM, Hayes MM and Gelmon KA: Ki67 in breast cancer: Prognostic and predictive potential. Lancet Oncol 11: 174-183, 2010.

36. Pachmann K, Clement JH, Schneider CP, Willen B, Camara O, Pachmann U and Höffken K: Standardized quantification of circulating peripheral tumor cells from lung and breast cancer. Clin Chem Lab Med 43: 617-627, 2005.

37. Tao M, Ma D, Li Y,Zhou C, Li Y, Zhang Y, Duan W, Xu X, Wang R, Wu L, et al: Clinical significance of circulating tumor cells in breast cancer patients. Breast Cancer Res Treat 129: 247-254, 2011.

38. Pachmann U, Hekimian K, Carl S, Ruediger N, Rabenstein C and Pachmann K: Comparing sequential steps for detection of circulating tumor cells: More specific or just less sensitive? Webmedcentral 2: WMC001490, 2011.

39. Lorente D, Ravi P, Mehra N, Pezaro C, Omlin A, Gilman A, Miranda M, Rescigno P, Kolinsky M, Porta N, et al: Interrogating metastatic prostate cancer treatment switch decisions: A multiinstitutional survey. Eur Urol Focus: S2405-4569(16): 30142-0, 2016. doi.org/10.1016/j.euf.2016.09.005.

40. Punnoose EA, Atwal SK, Spoerke JM, Savage H, Pandita A, Yeh RF, Pirzkall A, Fine BM, Amler LC, Chen DS, et al: Molecular biomarker analyses using circulating tumor cells. PLoS One 5: e12517, 2010.

41. Peeters DJ, van Dam PJ, Van den Eynden GG, Rutten A, Wuyts H, Pouillon L, Peeters M, Pauwels P, Van Laere SJ, van Dam PA, et al: Detection and prognostic significance of circulating tumour cells in patients with metastatic breast cancer according to immunohistochemical subtypes. Br J Cancer 110: 375-383, 2014

42. Liu Y, Liu Q, Wang T, Bian L, Zhang S, Hu H, Li S, Hu Z, Wu S, Liu B, et al: Circulating tumor cells in HER2-positive metastatic breast cancer patients: A valuable prognostic and predictive biomarker. BMC Cancer 13: 202, 2013.

43. Giordano A, Giuliano M, De Laurentiis M, Arpino G, Jackson S, Handy BC, Ueno NT, Andreopoulou E, Alvarez RH, Valero V, et al: Circulating tumor cells in immunohistochemical subtypes of metastatic breast cancer: Lack of prediction in HER2-positive disease treated with targeted therapy. Ann Oncol 23: 1144-1150, 2012

44. Arigami T, Uenosono Y, Hirata M, Yanagita S, Ishigami S and Natsugoe S: B7-H3 expression in gastric cancer: A novel molecular blood marker for detecting circulating tumor cells. Cancer Sci 102: 1019-1024, 2011.

45. Liu C, Liu J, Wang J, Liu Y, Zhang F, Lin W, Gao A, Sun M, Wang Y and Sun Y: B7-H3 expression in ductal and lobular breast cancer and its association with IL-10. Mol Med Rep 7: 134-138, 2013.

46. Urruticoechea A, Smith IE and Dowsett M: Proliferation marker Ki-67 in early breast cancer. J Clin Oncol 23: 7212-7220, 2005.

47. Müller V, Stahmann N, Riethdorf S, Rau T, Zabel T, Goetz A, Jänicke F and Pantel K: Circulating tumor cells in breast cancer: Correlation to bone marrow micrometastases, heterogeneous response to systemic therapy and low proliferative activity. Clin Cancer Res 11: 3678-3685, 2005 
48. Spiliotaki M, Mavroudis D, Kapranou K, Markomanolaki H, Kallergi G, Koinis F, Kalbakis K, Georgoulias V and Agelaki S: Evaluation of proliferation and apoptosis markers in circulating tumor cells of women with early breast cancer who are candidates for tumor dormancy. Breast Cancer Res 16: 485, 2014.

49. Kallergi G, Konstantinidis G, Markomanolaki H, Papadaki MA Mavroudis D, Stournaras C, Georgoulias V and Agelaki S: Apoptotic circulating tumor cells in early and metastatic breast cancer patients. Mol Cancer Ther 12: 1886-1895, 2013.

50. Nishimura R, Osako T, Okumura Y, Hayashi M, Toyozumi Y and Arima N: Ki-67 as a prognostic marker according to breast cancer subtype and a predictor of recurrence time in primary breast cancer. Exp Ther Med 1: 747-754, 2010.
51. Sun TW, Gao Q, Qiu SJ, Zhou J, Wang XY, Yi Y, Shi JY, Xu YF, Shi YH, Song K, et al: B7-H3 is expressed in human hepatocellular carcinoma and is associated with tumor aggressiveness and postoperative recurrence. Cancer Immunol Immunother 61: 2171-2182, 2012.

52. Kovarík J, Skry GD, Mikel J and Svoboda VH: Changes of Ki67 index of various tumors during radiation therapy. Neoplasma 43: 89-92, 1996.

53. Madu CO and Lu Y: Novel diagnostic biomarkers for prostate cancer. J Cancer 1: 150-177, 2010. 